\title{
Performed Diagnosis
}

National Cancer Institute

\section{Source}

National Cancer Institute. Performed Diagnosis. NCI Thesaurus. Code C93426.

The completed identification of a disease or illness by examining the signs and symptoms. 